\title{
Central Nervous System Hemorrhage Following Lumbar Puncture for Intrathecal Chemotherapy in a Pediatric Oncology Patient
}

\author{
Onur Balaban ${ }^{\mathrm{a}, \mathrm{d}}$, Giorgio Veneziano ${ }^{\mathrm{a}, \mathrm{b}}$, Richard S. Cartabuke, ${ }^{\mathrm{a}, \mathrm{b}}$, Joseph D. Tobias ${ }^{\mathrm{a}, \mathrm{b}, \mathrm{c}}$
}

\begin{abstract}
In the pediatric oncology patients, a lumbar puncture (LP) may be performed to administer intrathecal chemotherapy and obtain cerebrospinal fluid (CSF) samples. Although it is generally safe and devoid of adverse effects, with insertion and advancement of the spinal needle, there may be a risk of bleeding especially in patients with inherited or acquired defects of coagulation function. We report a 3-year-old child with acute lymphoblastic leukemia and associated thrombocytopenia who developed spinal and intraventricular hemorrhage following an LP for the administration of intrathecal chemotherapy. The etiology of such complications is discussed, previous reports are reviewed, and guidelines are suggested to prevent these complications.
\end{abstract}

Keywords: Subarachnoid hemorrhage; Thrombocytopenia; Lumbar puncture; Acute lymphoblastic leukemia; Pediatric

\section{Introduction}

In the pediatric oncologic population, lumbar puncture (LP) is commonly used for both diagnostic and therapeutic purposes. Although LP can generally be performed quickly without adverse consequences, congenital or acquired comorbid conditions affecting coagulation function may increase the risk of adverse effects. When regional anesthesia, including LP and spinal anesthesia, is performed in the perioperative setting, there are specific guidelines regarding its safety in the presence of coagulation dysfunction [1-3]. During the periopera-

Manuscript accepted for publication September 16, 2016

aDepartment of Anesthesiology \& Pain Medicine, Nationwide Children's Hospital, Columbus, $\mathrm{OH}, \mathrm{USA}$

${ }^{b}$ Department of Anesthesiology \& Pain Medicine, The Ohio State University, Columbus, $\mathrm{OH}$, USA

'Department of Pediatrics \& The Division of Pediatric Hematology/Oncology, The Ohio State University, Columbus, OH, USA

${ }^{\mathrm{d} C}$ Corresponding Author: Onur Balaban, Anesthesiology Department, Dumlupinar University, School of Medicine, Evliya Celebi Training and Research Hospital, Kutahya, Turkey. Email: obalabandr@gmail.com

doi: http://dx.doi.org/10.14740/jmc2656w tive period, it is generally recommended that the platelet count be greater than $100,000 / \mu \mathrm{L}$ for the elective performance of regional anesthesia; however, lower thresholds have been suggested for diagnostic and therapeutic LP in oncology patients $[4,5]$. The importance of such issues is illustrated by anecdotal case reports of hemorrhagic complications (spinal and epidural hematomas) after LP in patients with thrombocytopenia [5-7]. We report a 3-year-old child with acute lymphoblastic leukemia (ALL) and associated thrombocytopenia who developed spinal and intraventricular hemorrhage following an LP for the administration of intrathecal chemotherapy. The etiology of such complications is discussed, previous reports are reviewed, and guidelines are suggested to prevent these complications.

\section{Case Report}

Institutional Review Board approval at Nationwide Children's Hospital (Columbus, $\mathrm{OH}$ ) is not required for review and publication of single case reports. A 3-year-old, $16.1 \mathrm{~kg}$ girl with a diagnosis of ALL, presented for an LP and the administration of intrathecal chemotherapy under general anesthesia. The patient first presented with increased lethargy, bruises on her extremities, lymphadenopathy in the neck, and pallor. Prior to these complaints, the past medical and surgical history was negative. The patient was referred to our pediatric oncology department for further investigation and a complete blood count revealed anemia and leukocytosis with a white blood cell count of $55,000 / \mu \mathrm{L}$. Blasts were seen on the peripheral smear and acute lymphocytic leukemia was confirmed on bone marrow aspirate. Chemotherapy was initiated with thioguanine, vincristine, and cytosine arabinoside. Remission was induced and the patient was continued on maintenance chemotherapy. She presented 8 months later for sedation for an LP and intrathecal chemotherapy. Her pre-sedation evaluation revealed a hemoglobin of $10.2 \mathrm{~g} / \mathrm{dL}$, hematocrit of $30 \%$, and a platelet count of $45,000 / \mu \mathrm{L}$. Her physical examination was unremarkable and she was asymptomatic. There had been several previous uneventful LPs performed. For eight of these previous LPs, the platelet count was $\geq 149,000 / \mu \mathrm{L}$. For one, the platelet count was $35,000 / \mu \mathrm{L}$ and platelets were transfused immediately prior to the procedure.

Irradiated platelets were ordered and transfused the day prior to the LP; a post-transfusion platelet count was not ob- 


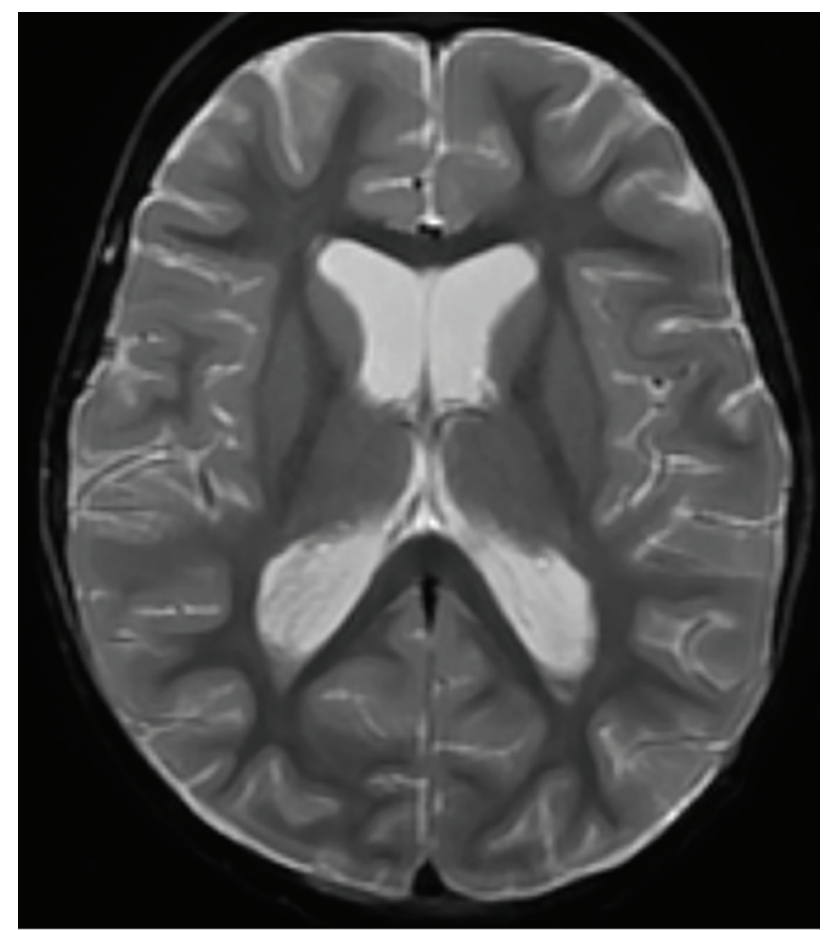

Figure 1. Magnetic resonance imaging of the brain showing intraventricular T2 hypointense signal compatible with intraventricular hemorrhage. Dependent layering is seen within the occipital horns of the lateral ventricles.

tained within the day of the procedure. Preoperative medications included thioguanine, ondansetron, polyethylene glycol, trimethoprim-sulfamethoxazole orally, nystatin topically and ophthalmic petrolatum mineral oil. Preoperative vital signs included a heart rate of 103 beats/min and a blood pressure (BP) of 104/72 mm Hg. The patient was held nil per os for $6 \mathrm{~h}$ and midazolam $(0.05 \mathrm{mg} / \mathrm{kg})$ was administered orally for premedication. She was transported to the operating room where routine monitors were applied according to American Society of Anesthesiologists' guidelines. The patient had a pre-existing central intravenous port which was used for the administration of intravenous propofol $(3 \mathrm{mg} / \mathrm{kg})$ for the induction of anesthesia. Maintenance anesthesia consisted of sevoflurane (end-tidal concentration 2-3.5\%) in 50\% oxygen/nitrous oxide with spontaneous ventilation. Ondansetron $(0.1 \mathrm{mg} / \mathrm{kg})$ was administered for the prevention of post-procedure nausea and vomiting. The patient tolerated anesthetic induction without adverse hemodynamic effects and was placed in the left lateral decubitus position. The lumbar site was prepared in a sterile manner and a 22-gauge, 2.5-inch spinal needle with stylet was advanced through the $\mathrm{L}_{4-5}$ interspace without difficulty. There were no technical problems noted with the performance of the LP. Five milliliter of clear and colorless cerebrospinal fluid (CSF) was collected and methotrexate $12 \mathrm{mg}$ was instilled into the intrathecal space without incident. The procedure lasted approximately $8 \mathrm{~min}$ with an anesthesia time of $22 \mathrm{~min}$. After recovery, the central venous port was flushed using $3 \mathrm{~mL}$ of 100 units $/ \mathrm{mL}$ heparin per institutional protocol before the patient was discharged from the post-anesthesia care unit and

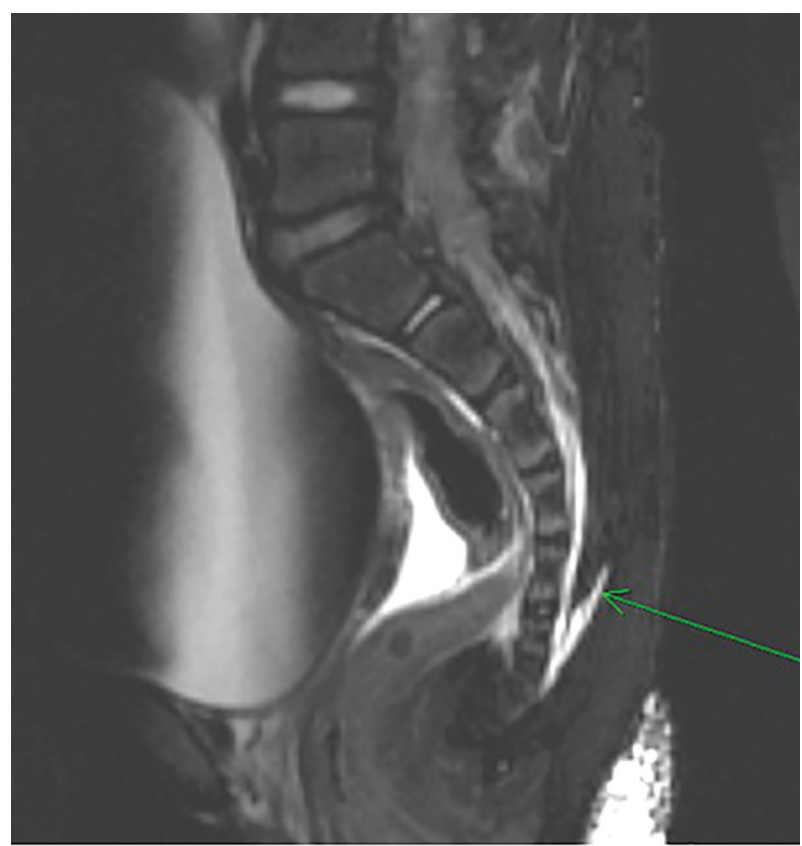

Figure 2. Magnetic resonance imaging (T2-weighted) showing blood filling the caudal aspects of the thecal sac (green arrow). Significant bladder distention is also noted anteriorly.

transferred back to the inpatient ward. The remainder of the post-procedure course was uneventful and the patient was discharged home. One day after the LP, the patient returned to the hospital with complaints of headache and bilateral leg pain. The headache had developed $3 \mathrm{~h}$ after the LP. It was occipital and worse when sitting up. Bilateral ("tickling") leg pain developed the night after the procedure. That morning, the headache and leg pain continued accompanied by new onset of neck pain. The patient did not report vision changes, photophobia or phonophobia. Her physical examination and vital signs showed no significant abnormalities. Laboratory findings included a white blood cell count of $3,200 / \mu \mathrm{L}$, hemoglobin of $8.5 \mathrm{~g} / \mathrm{dL}$, hematocrit of $24.6 \%$, and a platelet count of $33,000 / \mu \mathrm{L}$. Computed tomography of the head showed mild enlargement of the lateral and third ventricles with an area of hyper-attenuation in left frontal sulcus. Platelets $(10 \mathrm{~mL} / \mathrm{kg})$ were transfused to correct the thrombocytopenia. A magnetic resonance (MR) scan of the brain and spine was ordered and intravenous morphine was administered for pain. Differential diagnosis included postdural puncture headache from CSF leak, central nervous system (CNS) hemorrhage, epidural hematoma, or chemical versus infectious meningitis. The brain and spine magnetic resonance imaging (MRI) revealed diffuse intraventricular and subarachnoid hemorrhage of the brain (Fig. 1) and subarachnoid hematoma filling the caudal aspects of the thecal sac, with additional blood layering dorsally up to the mid-thoracic levels (Fig. 2). Neurosurgery consultation determined that there was no need for neurosurgical intervention, as examination of the patient did not reveal focal motor or sensory deficits. The neurosurgical team recommended anesthesiology consultation for treatment of the headache associated with LP. Gabapentin, acetaminophen, and caffeine were administered in addition 
to patient controlled analgesia with morphine. There were no progressive motor or sensory deficits. Her pain management was very problematic, requiring a 19-day hospital stay. Pain control eventually required the administration of systemic corticosteroids. Pain management was transitioned to oral medications including oxycodone and amitriptyline with the addition of clonidine. Follow-up MRI studies revealed a resolution of subarachnoid and intraventricular blood in the brain and subarachnoid hematoma in the caudal aspects of the thecal sac as well as an interval decrease in the size of the ventricular system. Follow-up in the outpatient pain clinic revealed progressive decrease in the pain over the ensuring 2 weeks.

\section{Discussion}

Common complications of diagnostic LP procedures include localized bruising, back pain, headache, and radiculopathy. Most are minor, more commonly seen in adults, transient, and resolve spontaneously without intervention [8]. More serious complications, although rare, include intracranial hemorrhage, abscess formation, sinus tract formation, epidermoid tumor formation, and epidural or subdural spinal hematomas [9]. Mortality is exceedingly rare, generally the result of brainstem herniation from rapid CSF removal when there is increased intracranial pressure [8].

Although uncommon, significant morbidity may result from hemorrhagic complications following LP, as was the case with our patient who developed local bleeding at the level of the LP and CNS bleeding distant from the procedure site. Neuraxial bleeding complications most commonly follow an LP in patients with abnormal coagulation function, either pharmacologically induced or those resulting from systemic diseases [10, 11]. In the absence of bleeding disorders, complications from LP are rare. The majority of case reports and all large series describing hemorrhagic complications following diagnostic or therapeutic LP are in the adult population. Ayerbe et al reported the development of an intradural hematoma following LP in a 20-year-old man with leukemia and thrombocytopenia (platelet count of $26,000 / \mu L$ ) [5]. Paraparesis and an inability to stand developed requiring an emergency decompressive laminectomy. The authors subsequently reviewed the literature and found only 26 cases of neuraxial hemorrhagic complications after LP. In the majority of cases, they noted common features including acquired coagulation defects with thrombocytopenia, abnormalities in synthetic coagulation function, or ongoing therapeutic anticoagulation. Despite this, they noted good functional outcome in approximately half of the patients with early identification and surgical intervention. In some cases, the onset of symptoms was delayed, being days beyond the initial procedure.

Adler et al reported a single case of a hemorrhagic complication following an LP and then reviewed 64 cases of spinal hematomas secondary to LP over a 22-year time span from 1966 to 1998 [9]. The authors reported a 5-year-old boy in whom a diagnostic LP was performed to rule out meningitis in the presence of fever and vomiting. He complained of thigh and back pain approximately $4-5 \mathrm{~h}$ after the procedure with a questionable change in his neurologic examination (upgo- ing toes with plantar stimulation). Coagulation functions including prothrombin time (PT), partial thromboplastin time (PTT), international normalized ratio (INR), and platelet count were normal. MRI of the thoracolumbar spine revealed epidural blood extending from L4-5 up to L2 with compression of the thecal sac. There was no progression of his neurologic symptoms and no surgical intervention was deemed necessary. His neurologic symptoms and pain resolved. Of the 64 cases that this group identified from the literature, only 10 were in patients less than 20 years of age. Forty $(63 \%)$ of the cases involved diagnostic LP. Abnormalities of the coagulation cascade were noted in $78 \%$ of the cases; however, the majority of these $(64 \%)$ were the result of therapeutic anticoagulation, generally intravenous heparin which was employed during or initiated soon after the procedure. Of the cases with nonpharmacologic induced coagulopathy, there were 11 cases of leukemia, 12 cases of hepatic failure, 13 cases of leptospirosis, and an infant with undiagnosed hemophilia.

Howard et al retrospectively reviewed the performance of LP in a cohort of 958 consecutive children with newly diagnosed ALL over a 4-year period [12]. All patients underwent a diagnostic LP followed by a median of four LPs to instill intrathecal chemotherapy. Of the 5,223 LPs evaluated, 29 were performed with a platelet count $\leq 10,000 / \mu \mathrm{L}, 170$ at a platelet count of $11,000-20,000 / \mu \mathrm{L}$, and 742 at a platelet count of $21,000-50,000 / \mu \mathrm{L}$. No serious complications were encountered, regardless of the platelet count. The 95\% confidence interval for the proportion of serious complications in the 199 patients with a platelet count of $\leq 20,000 / \mu \mathrm{L}$ was $0-1.75 \%$ and $0-0.37 \%$ for patients with a platelet count of $\leq 50,000 / \mu \mathrm{L}$. Due to the small number of patients in the study, they were unable to offer recommendations for patients with a platelet count of $\leq 10,000 / \mu \mathrm{L}$. They concluded that prophylactic platelet transfusion is not necessary in children with platelet counts higher than $10 \times 10^{9} / \mathrm{L}(10,000 / \mu \mathrm{L})$.

From review of the literature, it is evident that hemorrhage after LP is very rare in children. The authors found only five pediatric cases reported in the literature when using the search words "hemorrhage" or "hematoma" and "lumbar puncture" and "pediatric". These cases are summarized in Table 1 [7, 9, 13-15]. Of these, the one that is most similar to the case reported herein is a 12-year-old boy with ALL and thrombocytopenia (platelet count $42,000 / \mu \mathrm{L}$ ) who underwent a diagnostic LP [15]. Although a platelet transfusion was performed immediately before the LP, a repeat platelet count was not obtained prior to the procedure. Shortly after the LP, an extensive spinal subdural hematoma developed from the T2 to S2 level presenting with paraparesis. Surgical decompression was required and motor function eventually recovered.

Specific practice guidelines regarding the acceptable platelet count for the performance of an LP in the pediatric vary according to the source. As noted above, some authors suggest that above $10,000 / \mu \mathrm{L}$ is safe based on retrospective data. The British Committee for Standards in Hematology suggested a minimum platelet count of $50,000 / \mu \mathrm{L}$ prior to performance of an LP [4]. A subsequent review of 17 national and international guidelines from blood transfusion and anesthesia societies suggested that a platelet count of $\geq 40,000 / \mu \mathrm{L}$ is acceptable for performance of an LP, provided that the platelet 
Table 1. Previous Reports of Hemorrhagic Complications After Lumbar Puncture in Children

\begin{tabular}{|c|c|c|c|c|c|}
\hline Author & Case & $\begin{array}{l}\text { Hemorrhagic } \\
\text { complication }\end{array}$ & Procedure & $\begin{array}{l}\text { Coagulation } \\
\text { disorder }\end{array}$ & Neurologic deficit, therapies, and outcome \\
\hline $\begin{array}{l}\text { Hatzipantelis } \\
\text { et al [7] }\end{array}$ & $\begin{array}{l}\text { 5-year-old } \\
\text { boy with ALL }\end{array}$ & $\begin{array}{l}\text { Epidural } \\
\text { hematoma }\end{array}$ & LP & Thrombocytopenia & $\begin{array}{l}\text { Headache and lower back pain with paraparesis, } \\
\text { decreased sensation of both legs, and urinary retention } \\
\text { after LP. Sensation of lower extremities was recovered } \\
\text { quickly, whereas motor function of legs improved } \\
\text { gradually. Urinary retention followed a slower course } \\
\text { of recovery. }\end{array}$ \\
\hline $\begin{array}{l}\text { Boran et } \\
\text { al [13] }\end{array}$ & $\begin{array}{l}6 \text {-year-old } \\
\text { boy with } \\
\text { non-Hodgkin } \\
\text { lymphoma }\end{array}$ & $\begin{array}{l}\text { Fronto- } \\
\text { parietal } \\
\text { hematoma }\end{array}$ & $\begin{array}{l}\text { LP for IT } \\
\text { chemotherapy }\end{array}$ & None & $\begin{array}{l}\text { Right hemiparesis and focal seizures. Neurosurgery } \\
\text { team recommended surgical evacuation of the } \\
\text { hematoma, but the parents refused. The intracerebral } \\
\text { hematoma resolved spontaneously over } 6 \text { weeks and } \\
\text { the patient's symptoms improved. }\end{array}$ \\
\hline $\begin{array}{l}\text { Tubbs et } \\
\text { al [14] }\end{array}$ & Preterm infant & $\begin{array}{l}\text { Conus } \\
\text { medullaris } \\
\text { hematoma }\end{array}$ & LP & None & $\begin{array}{l}\text { Spontaneous movement of the lower extremities } \\
\text { decreased after LP. Residual neurologic deficit with } \\
\text { lower extremity paresis and incontinence of bowel and } \\
\text { bladder. }\end{array}$ \\
\hline $\begin{array}{l}\text { Wirtz et } \\
\text { al [15] }\end{array}$ & $\begin{array}{l}\text { 12-year- } \\
\text { old boy }\end{array}$ & $\begin{array}{l}\text { Spinal } \\
\text { subdural } \\
\text { hematoma }\end{array}$ & LP & Thrombocytopenia & $\begin{array}{l}\text { Lower back pain, leg weakness, and urinary retention } \\
\text { developed after LP. Surgical laminectomy was } \\
\text { performed from T11 to L2 with partial evacuation of } \\
\text { the hematoma. After surgery, his neurologic condition } \\
\text { gradually improved. He was able to walk without } \\
\text { support and urinary retention had resolved. }\end{array}$ \\
\hline
\end{tabular}

ALL: acute lymphoblastic lymphoma; LP: lumbar puncture; MRI: magnetic resonance imaging; IT: intrathecal.

count is stable, there is no other acquired or congenital coagulopathy, the platelet function is normal, and the patient is not on medications affecting coagulation function [16]. These reviewers found the published evidence insufficient to make recommendations for a platelet count of $\leq 40,000 / \mu \mathrm{L}$ and suggested that an individual risk/benefit decision should be made in patients with a platelet count between 20,000 and 40,000/ $\mu \mathrm{L}$. The group further suggested that the safety of an LP depends not only on the number of platelets, but also on other factors, such as the experience of the practitioner, immobility of the child, the presence of coagulopathy, defects in the platelet function, and on how fast the platelet count decreases. Of note, while guidelines from both the American and European Societies of Regional Anesthesia exist regarding the performance of neuraxial anesthesia in the presence of medications that affect coagulation function, they do not specifically address the platelet count $[2,3]$. Others have anecdotally suggested the potential use of recombinant factor VIIa [17]. Additionally, although it makes intuitive sense that use of a smaller needle may limit the risk of trauma, there is no evidence-based medicine to demonstrate the benefit of the use of a smaller needle. However, the benefit of such a practice has been demonstrated to decrease the incidence of post-dural puncture headache in both adult and pediatric patients [18-20]. Given that there is no documented clinical benefit to the use of a larger needle, we would suggest limiting the size of the spinal needle to no greater than 22 gauges.

An additional factor contributing to bleeding may be the heparin flush used prior to central line removal. In this patient, $3 \mathrm{~mL}$ of heparin $(100 \mathrm{IU} / \mathrm{mL})$ was administered per protocol to "lock the port", 20 min after LP procedure. Additionally, the port was used as an intravenous line during the operation. There is no information from the medical record as to how the port was used intraoperatively, as to when the last time the port had been flushed, and whether the port was aspirated prior to the infusion of intravenous fluids. Although common practice in most institutions, it is unknown what impact these practices have on coagulation function especially in patients with concomitant thrombocytopenia or platelet dysfunction [21, 22]. Lower doses of heparin and normal saline solution may be as effective with less impact on coagulation function [21, 22].

In our patient, although platelets were transfused, a subsequent platelet count was not obtained prior to performing the LP. As several factors may impact the platelet count obtained following the transfusion of allogeneic platelets, a follow-up evaluation is suggested to ensure that an acceptable level has been achieved. Our patient developed both a local hemorrhagic complication at the site of the LP as well as bleeding within the CNS. These findings emphasize the potential impact of coagulation function on bleeding at various sites within the 
spine and CNS. The bleeding at the site of the procedure is likely related to direct trauma to the vasculature within and surrounding the epidural space. Boran et al present an elegant discussion regarding the potential pathophysiology responsible for the CNS bleeding that was noted in their patient and ours [13]. With the removal of CSF during LP and the ongoing leak that may occur following the procedure, there may be a decrease in intracranial pressure (ICP), leading to secondary increase in the volume of intracerebral veins. Additionally, the loss of CSF and the decreased ICP also cause caudal displacement of intracranial structures, applying traction on the dilated veins. This may result in tearing of the dilated veins leading to subdural or intracerebral hematoma formation. In addition, it has been suggested that the administration of methotrexate may also play a role in this process, as there are no reports of intracerebral or subdural hematoma following diagnostic LP.

Subarachnoid hemorrhage after LP in a pediatric patient is very rare, even in patients with an underlying bleeding disorder or thrombocytopenia. The associated coagulation defect (platelets or synthetic function) may be congenital or acquired, related to therapeutic use of anticoagulation. While there is limited evidence-based medicine to support recommendations, it remains routine clinical practice to measure coagulation function prior to neuraxial (spinal or epidural) procedures in anesthetic practice. However, this does not appear to be the case prior to diagnostic LP in the pediatric population. We continue to recommend that all anticoagulation medications be held surrounding the performance of LP and that normal coagulation be documented whenever possible prior to the procedure. Conservative guidelines would be to ensure an INR $\leq 1.4$, a normal PTT, and a platelet count greater than 100,000/ $\mu \mathrm{L}$. If intervention is provided to correct abnormal values, we would suggest obtaining follow-up laboratory values to verify that therapeutic correction has been accomplished. Regardless of these steps, patients should be carefully assessed following neuraxial procedures. Alterations in motor or sensory function, bowel or bladder dysfunction, changes in neurologic status, or pain should be immediately evaluated, diagnostic imaging should be ordered, and neurosurgical consultation should be obtained. As noted in our patient, effective pain control can be difficult due to the resultant inflammatory process related to the presence of blood. In our patient, we noted limited success with the use of opioids and found the addition of adjuncts useful, including benzodiazepines to control muscle spasms, clonidine, and gabapentin. This patient obtained significant pain relief from the addition of corticosteroids (dexamethasone). Given their effects on platelet function, we would caution against the use of non-steroidal anti-inflammatory agents.

\section{Conflicts of Interest}

None.

\section{Grant Support}

None.

\section{References}

1. Narouze S, Benzon HT, Provenzano DA, Buvanendran A, De Andres J, Deer TR, Rauck R, et al. Interventional spine and pain procedures in patients on antiplatelet and anticoagulant medications: guidelines from the American Society of Regional Anesthesia and Pain Medicine, the European Society of Regional Anaesthesia and Pain Therapy, the American Academy of Pain Medicine, the International Neuromodulation Society, the North American Neuromodulation Society, and the World Institute of Pain. Reg Anesth Pain Med. 2015;40(3):182-212.

2. Horlocker TT. Regional anaesthesia in the patient receiving antithrombotic and antiplatelet therapy. Br J Anaesth. 2011;107(Suppl 1):i96-106.

3. Horlocker TT, Wedel DJ, Rowlingson JC, Enneking FK, Kopp SL, Benzon HT, Brown DL, et al. Regional anesthesia in the patient receiving antithrombotic or thrombolytic therapy: American Society of Regional Anesthesia and Pain Medicine Evidence-Based Guidelines (Third Edition). Reg Anesth Pain Med. 2010;35(1):64-101.

4. Guidelines for the use of platelet transfusions. Br J Haematol. 2003;122(1):10-23.

5. Ayerbe J, Quinones D, Prieto E, Sousa P. [Spinal subarachnoid hematoma after lumbar puncture in a patient with leukemia: report of a case and review of the literature]. Neurocirugia (Astur). 2005;16(5):447-452.

6. Edelson RN, Chernik NL, Posner JB. Spinal subdural hematomas complicating lumbar puncture. Arch Neurol. 1974;31(2):134-137.

7. Hatzipantelis E, Kyriakidis I, Pavlou E, Pavlidou E, Stamou M, Foroglou N, Papageorgiou T, et al. Lumbar puncture complicated by spinal epidural hematoma in a child with leukemia. Clin Case Rep. 2015;3(6):388-391.

8. Bonadio W. Pediatric lumbar puncture and cerebrospinal fluid analysis. J Emerg Med. 2014;46(1):141-150.

9. Adler MD, Comi AE, Walker AR. Acute hemorrhagic complication of diagnostic lumbar puncture. Pediatr Emerg Care. 2001;17(3):184-188.

10. Domenicucci M, Ramieri A, Paolini S, Russo N, Occhiogrosso G, Di Biasi C, Delfini R. Spinal subarachnoid hematomas: our experience and literature review. Acta Neurochir (Wien). 2005;147(7):741-750; discussion 750.

11. Foerster MV, Pedrosa Fde P, da Fonseca TC, Couceiro TC, Lima LC. Lumbar punctures in thrombocytopenic children with cancer. Paediatr Anaesth. 2015;25(2):206210.

12. Howard SC, Gajjar A, Ribeiro RC, Rivera GK, Rubnitz JE, Sandlund JT, Harrison PL, et al. Safety of lumbar puncture for children with acute lymphoblastic leukemia and thrombocytopenia. JAMA. 2000;284(17):2222-2224.

13. Boran P, Tokuc G, Boran BO, Oktem S. Intracerebral hematoma as a complication of intrathecal methotrexate administration. Pediatr Blood Cancer. 2008;50(1):152-154.

14. Tubbs RS, Smyth MD, Wellons JC, 3rd, Oakes WJ. Intramedullary hemorrhage in a neonate after lumbar puncture resulting in paraplegia: a case report. Pediatrics. 2004;113(5):1403-1405. 
15. Wirtz PW, Bloem BR, van der Meer FJ, Brouwer OF. Paraparesis after lumbar puncture in a male with leukemia. Pediatr Neurol. 2000;23(1):67-68.

16. van Veen JJ, Nokes TJ, Makris M. The risk of spinal haematoma following neuraxial anaesthesia or lumbar puncture in thrombocytopenic individuals. $\mathrm{Br} \mathrm{J}$ Haematol. 2010;148(1):15-25.

17. Das P, Carcao M, Hitzler J. Use of recombinant factor VIIa prior to lumbar puncture in pediatric patients with acute leukemia. Pediatr Blood Cancer. 2006;47(2):206209.

18. Lee LC, Sennett M, Erickson JM. Prevention and management of post-lumbar puncture headache in pediatric oncology patients. J Pediatr Oncol Nurs. 2007;24(4):200207.

19. Doherty CM, Forbes RB. Diagnostic Lumbar Puncture.
Ulster Med J. 2014;83(2):93-102.

20. Armon C, Evans RW. Addendum to assessment: Prevention of post-lumbar puncture headaches: report of the Therapeutics and Technology Assessment Subcommittee of the American Academy of Neurology. Neurology. 2005;65(4):510-512.

21. Rosenbluth G, Tsang L, Vittinghoff E, Wilson S, WilsonGanz J, Auerbach A. Impact of decreased heparin dose for flush-lock of implanted venous access ports in pediatric oncology patients. Pediatr Blood Cancer. 2014;61(5):855858 .

22. Bertoglio S, Solari N, Meszaros P, Vassallo F, Bonvento M, Pastorino S, Bruzzi P. Efficacy of normal saline versus heparinized saline solution for locking catheters of totally implantable long-term central vascular access devices in adult cancer patients. Cancer Nurs. 2012;35(4):E35-42. 